\title{
Keeping faculty current
}

\author{
By Debra Hassig \\ Reference Librarian \\ Lehman Library, Columbia University
}

and David W. Lewis

Lehman Librarian

Columbia University

\section{An inexpensive, efficient way to distribute tables of}

contents.

\begin{abstract}
Some years ago, in an analysis of the economics of academic libraries, Yale M. Braunstein made a plea for considering the user's costs, mainly the cost of time, when we design library services. ${ }^{1}$ Unfortunately, the financial constraints of academia and the press of expanding information sources has made it difficult for most academic libraries to consider providing new services designed to make access to collections easier from the user's point of view.

The service described below is an example of an attempt to heed Braunstein's plea by providing the faculty with valuable information in a manner that saves them considerable time and effort. What is important about this example is not that it is a revolutionary idea, for it is certainly not unique. What is important is that it is cheap and it works. For less than half the cost of adding a new book to our collection, we can provide an individual with a year's worth of a service that, as one faculty member described it, "has saved me a great deal of effort and has made a significant impact on the way in which I do my scholarly work." With a little effort, we have provided a valued service to our faculty and in the process have netted the library good will.
\end{abstract}

\section{Table of Contents service}

The Table of Contents service of the Lehman Li-

\footnotetext{
${ }^{1}$ Yale M. Braunstein, "Costs and Benefits of Library Information: The User's Point of View", Library Trends 28 (Summer 1979):79, 82.
}

brary provides copies of the tables of contents of selected journals to members of the faculty. Each individual is free to choose any twenty titles to which the library subscribes. Photocopies of the contents pages are made and mailed to the faculty members within two days of receipt of the journal in the library.

The current service is an adaptation of an earlier and less successful program. Our first attempt involved compiling monthly packets of journal contents pages for the disciplines of anthropology, sociology, political science, and international affairs. These packets were distributed to departments and in some cases to individual faculty members; they were also available in a number of library locations. This involved collecting all of the journals once a month, photocopying literally thousands of pages, and collating the packets before mailing.

In addition to the considerable time and effort required to compile the packets, the program had a number of failings that became increasingly evident. Various comments revealed that from the faculty viewpoint, receiving such massive amounts of material all at once proved difficult to deal with effectively. This was particularly true for individuals with interdisciplinary interests who received more than one packet. There was also a substantial time lag between any given journal's receipt in the library and the compilation of the packets; as a result of this lag, many journals which had been received could not be included because they were misplaced or in use when the packets were com- 
piled. Finally, the packets contained many titles that simply were not of interest to many of the faculty members receiving them. It became clear that we needed a service that was timely, more effectively targeted, and that required less effort to process.

In September 1984, 200 faculty members were mailed a letter explaining the new service with a list of the new titles that had been part of the earlier disciplinary packets. They were invited to select from these titles or to choose any others to which the library subscribed. In response to the mailing, 81 faculty members returned the lists. Most of these were in the social science departments that are the library's primary clientele, but others included members of area studies institutes from a wide variety of departments.

Using list and sort programs available on the library's DECmate II microcomputer, these lists were processed and sorted by title. Cards were produced for each title requested with the name and address of all those requesting the title. The availability of the microcomputer made possible the manipulation and updating of this file, a task that would have otherwise been tedious and timeconsuming at best. Without this computerized facility we would probably not have undertaken the project. The Kardex was then tagged for all of the titles in the service. When a title is checked in and found to be part of the service, it is put aside. Every day a student assistant picks up the issues, and after matching them to the cards, photocopies the contents pages with the cards, returns the issues to the to-be-shelved area, and refiles the cards. The photocopied information from the cards serves as the mailing labels, so the copies are simply folded, stapled and mailed.

\section{Costs}

An analysis of the annual cost of implementing and maintaining the service shows that the current system represents about a $50 \%$ savings over the previous program. The most dramatic cost reduction is in student assistant time, which was cut from 30 hours per month to 10 hours per month, resulting in a savings of nearly $70 \%$. Photocopying charges represent a $50 \%$ savings. Costs for the current service not incurred under the old system are word processing, marking of Kardex periodicals records, and a measurable, albeit minimal, amount of professional time. However, with the savings on student time and photocopying, even these additional charges bring the annual total to about one-half the cost of the previous program. On a more detailed level, annual costs are as follows: per faculty member, $\$ 20.00$; per journal, $\$ 1.30$; per item mailed, $\$ 0.13$.

A summary of the annual costs of both the previous and current services is given below. These estimates are based on current wages at Columbia: $\$ 5.00$ per hour for student assistants, $\$ .05$ per page for photocopying, and $\$ 11.00$ per hour for beginning professional librarian. Local mailing cost is not included.

Previous service total: $\$ 3,135.00$

1) staff: $\$ 1,800.00$

2) photocopying: $\$ 1,285.00$

3) office supplies: $\$ 50.00$

Current service total: $\$ 1,650.00$

1) staff: $\$ 950.00$

2) photocopying: $\$ 650.00$

3) office supplies: $\$ 50.60$

\section{Evaluation}

Approximately $75 \%$ of the individual lists reflected preferences that could not have been satisfied with any one of the formerly-issued subject packets. Fifty-five percent of the lists showed either an interdisciplinary (i.e., two or more disciplines) interest or a single disciplinary interest with a particular area focus. Twenty percent of the lists showed both interdisciplinary and area interests. The remaining quarter of the lists contained selections within a single discipline. The percentage of interdisciplinary lists was not concentrated in any one department. For example, an anthropologist requested anthropology, sociology, and political science journals in addition to those pertaining specifically to Latin American studies. A faculty member in the Southern Asian Institute requested not only Asian studies journals but also titles in anthropology, sociology, and political science. A political scientist selected journals in political science, sociology and two different areas (USSR and Latin America); a sociologist's list indicated interest in sociology, anthropology, and political science journals.

\section{Questionnaire results}

Many of the faculty lists received at the onset of the service included enthusiastic written commentary, generally extolling the value of such a current awareness service. However, these comments were made prior to the actual instigation of the system; it remained to be seen if and how well the system would actually work. In order to make a more accurate evaluation, a short questionnaire was sent to participating faculty in April, after the system had been running for nearly two semesters. Its purpose was threefold: 1) to find out if the mechanics (i.e., the sorting and mailing processes) were working properly; 2) to see if in fact useful books and articles were being brought to the faculty's attention as a result of the service; and 3) to gather any suggestions for improvement of the service.

Response to the questionnaire was quite good; 55 of the 81 faculty responded by the deadline. The fact that the questionnaire accompanied a request for renewal of the service certainly helped the response rate.

It appeared from the results of the questionnaire 
that the system was working effectively. Over half of the faculty had received four or more table of contents pages in the last two weeks. Less than $4 \%$ had received no table of contents pages during that period. Most faculty reported that the service had regularly brought items to their attention that they subsequently wanted to read. At least one useful item was reported identified in the last two weeks by $94 \%$ of the respondents. Of these, $64 \%$ indicated that one to three items were brought to their attention, $19 \%$ reported four to six items, and $11 \%$ reported that more than six wanted items were discovered through the service during the last two weeks. As a general rule, it seemed that each table of contents page the faculty member received led to the discovery of one article of interest. These results, in conjunction with the enthusiastic comments that the questionnaire generated, lead us to believe that the service does fulfill its intended purpose.

The comments written on the questionnaire had two common themes: the service not only saved time (one faculty member estimated this at an afternoon a month) but extended the faculty's scope beyond what had been made possible without the service. As one respondent wrote, "This service is enormously useful. It does not merely make easier something I would otherwise do for myself but enables me to extend my normal literature review beyond what I used to do for myself. And I have found many things to read.'

The questionnaire produced two other findings. When asked how much success they had experienced in locating in the library those items discovered through the service, only about $40 \%$ had located all of the items, $30 \%$ had located $75 \%$ of the items, and the last $30 \%$ had located $50 \%$ or less.
This was a clear indication that we need to work harder at shelving our current periodicals area. It was not what we wanted to hear, but it was a useful reminder. When asked if they would like the service extended to other Columbia University libraries, $90 \%$ said yes. The list of libraries includes half of the libraries in the Columbia system. This is yet another indicator of the diversity of faculty interests and their interdisciplinary needs.

\section{Conclusion}

The current Table of Contents service not only has the discussed advantages over the previous program and the blessing of the faculty, but also is more efficient and effective than other available social sciences SDI services, such as computerized update systems or commmercially published weeklies and monthlies. Computerized SDI services, such as those performed using DIALOG or BRS and Social SciSearch or PAIS (Public Affairs Information Service), do the job, but require a significant amount of professional time and represent an ongoing expense for the customer. Published sources, such as Current Contents: Social and Behavioral Sciences or ABC Pol Sci, do not offer customized or as wide a selection of journals and are not as frequent as the Table of Contents daily operation. They also require a trip to the library. Neither computerized nor published SDI services are coordinated with the holdings of Lehman Library: the Table of Contents service is designed to inform faculty of both the contents and availability of selfselected periodicals. It does so in a timely manner, at no cost to the recipients (either in dollars or, perhaps more importantly, in time), and at a minimal cost to the library.

\section{TABLE OF CONTENTS QUESTIONNAIRE}

1. During the past two weeks, for how many periodical issues did you receive contents pages via the Table of Contents service?

$$
\text { none 4-6 - } \quad \text {-3 more than } 6
$$

If none, go to question 4 .

2. During the past two weeks, how many articles or books that you subsequently wanted to read did you discover via your Table of Contents mailings?

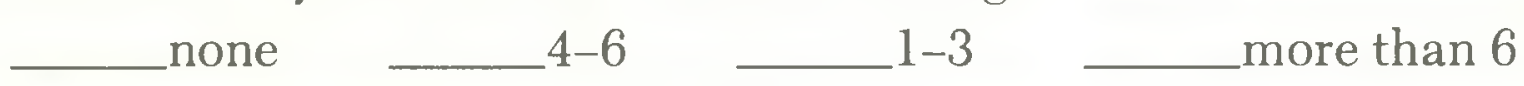

If none, go to question 4 .

3. During the past two weeks, approximately how much success did you or an assistant have in locating periodical issues in Lehman Library that were needed for photocopying or reading articles identified via the Table of Contents service?

$\begin{array}{cr}\text { found all issues } & \text { found } 50 \% \text { of issues } \\ \text { found } 75 \% \text { of issues } & \text { found } 25 \% \text { of issues }\end{array}$

found no issues

4. Would you like to see this service coordinated to include mailings from periodicals received in other Columbia libraries in addition to Lehman Library? yes_no If not, go to question 6.

5. Which Columbia Libraries in addition to Lehman Library would you like to see included? Business Library _ Science Library Butler Library (humanities and history) Other, which one(s)?

6. Please write any additional comments and/or suggestions in the space below or on the back of this page. 